\title{
Optimization design of a RC slab under impact load using DPSO-based multiple optimal solutions
}

\author{
M. Beppu ${ }^{1}$, H. Emoto ${ }^{2}$, H. Nakamura ${ }^{2}$ \& A. Miyamoto ${ }^{2}$ \\ ${ }^{1}$ Department of Civil and Environmental Engineering, \\ National Defense Academy, Japan \\ ${ }^{2}$ Department of Computer and Systems Engineering, \\ Yamaguchi University, Japan
}

\begin{abstract}
This study presents an application of optimization algorithm to design of reinforced concrete (RC) slab under impact load. Firstly, a novel stochastic search algorithm termed discrete particle swarm optimization (DPSO) and its improvement is explained to obtain multiple optimal solutions. Then, the newly developed algorithm is applied to optimization design of RC slab under impact load. In this procedure, FE analysis is employed to evaluate the dynamic behavior of RC slab. As a result, possibility and reliability of optimization design of RC slab under impact load was demonstrated.
\end{abstract}

Keywords: discrete particle swarm optimization, RC slab, impact load.

\section{Introduction}

In order to design structures which can resist impact/impulsive load, it is necessary to investigate the index for structural safety. Especially in case an impact resistance performance is examined by using numerical analysis, it is necessary to make sure the influence of analytical parameters on results. However, it is extremely difficult to carry out these procedures because impact/impulsive behavior of concrete structures are very complicated. In practical structural optimization design, the genetic algorithms (GAs) [1], as powerful and applicable stochastic search and optimization algorithms, are finding increasing use for solving combinatorial problem. 
This study presents an attempt to apply optimization algorithm to design of reinforced concrete (RC) slab under impact load. Firstly, a novel stochastic search algorithm termed discrete particle swarm optimization (DPSO) and its improvement is explained to obtain multiple optimal solutions. Then, the newly developed algorithm is applied to optimization design of RC slab under impact load. FE analysis is employed to evaluate the dynamic behavior of RC slab. As a result, possibility and reliability of optimization design of $\mathrm{RC}$ slab under impact load was demonstrated.

\section{Outline of discrete particle swarm optimization algorithm}

Particle swarm optimization (PSO) is a population based stochastic optimization technique developed by James Kennedy and Russel Eberhart [2] in 1995, inspired by social behavior of bird flocking or fish schooling. In PSO, solutions are called as particles, and particles have information of position (searching points) and velocity which direct the flying of the particles. Each particle has information of the previous best position, called "pBest". The particle swarm optimizer tracked the best value, obtained so far by any particle in the swarm. The best value " $g$ Best" is a global best solution in swarm.

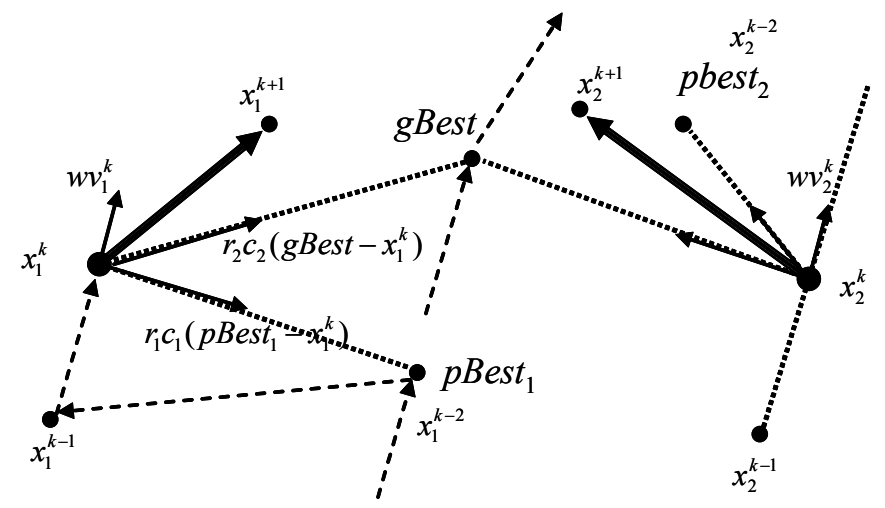

Figure 1: Outline of moving particles.

PSO method searches the solution based on current position, $p B e s t_{i}$ and $g B e s t$ through the problem space. Particle position is updated by summing vector values as shown in fig. 1. Here, $x_{1}^{k}$ and $x_{2}^{k}$ represent information of position of search point, $v_{1}^{k}$ and $v_{2}^{k}$ represent particle velocities, superscript $k$ represents the number of iteration, $w$ represents inertia weight, $c_{1}$ and $c_{2}$ represent learning coefficient, $r_{1}, r_{2}$ represent uniform random number between [0,1]. Take $x_{1}^{k+1}$ for example, $x_{1}^{k+1}$ is represented by linear combination of $\left(v_{1}^{k}\right),\left(g B e s t-x_{1}^{k}\right)$ and $\left(p\right.$ Best $\left._{1}-x_{1}^{k}\right) .\left(v_{1}^{k}\right)$ means previous velocity of particle1. (gBest $\left.-x_{1}^{k}\right)$ 
means the global search, which directs the best solution in swarm. $\left(\right.$ pBest $\left._{1}-x_{1}^{k}\right)$ indicates to direct the own particle best solution in each particle, which is practically a local search procedure. Generally velocity of $i$-th particle in $(k+1)$-th step is calculated in the form as.

$$
v_{i}^{k+1}=w v_{i}^{k}+\frac{r_{1} c_{1}\left(p \text { Best }_{i}-x_{i}^{k}\right)}{\Delta t}+\frac{r_{2} c_{2}\left(g B e s t-x_{i}^{k}\right)}{\Delta t}
$$

Position of search point is calculated by

$$
x_{i}^{k+1}=x_{i}^{k}+v_{i}^{k+1} \Delta t
$$

Ordinary PSO algorithm provides only one optimal solution. In view of practical structural design, provision of possible multiple suboptimal solutions is desirable. In this study, discrete type of PSO (DPSO) [3] is used and improved by adopting ecological logic below to provide multiple suboptimal solutions.

- Conserve species of dominance

Species of dominance is most dominance in the particles. When similar particles exist, the particle is conserved as a species of dominance.

- Havoc

A havoc indicates unexpected change of environment of habitat, for example, typhoon, forest fire, flood, etc.. If a havoc happened, species of dominance is supposed to decrease suddenly. Havoc also results in a mitigation of competition among species and degree of diversity of particles comes to be higher.

- Turnover of species

A turnover of species means movement of species in the habitat. If current species is identified to previous species of dominance, the current species moves to other habitant.

The procedure of the improved DPSO as shown in fig. 2 is described as follows:

Step1: Initialize particle

Initial position (searching points) and velocity of each particle are generated randomly within the allowable range.

Step2: Calculate evaluation value and conserve species of dominance

The objective function value is calculated for each particle. Position of each particle is decoded as input data for numerical analysis.

Then, the affinity between particle $i$ and $j$ is calculated by

$$
\text { affinity }_{i, j}=1 /\left(1+H_{i, j}\right)
$$

where $H_{i, j}=$ Hamming distance (i.e., similarity) between particle $i$ and $j$.

The concentration $c_{i}$ of particle $i$ is given by

$$
c_{i}=\sum_{j=1}^{N} a c_{i, j} / N
$$




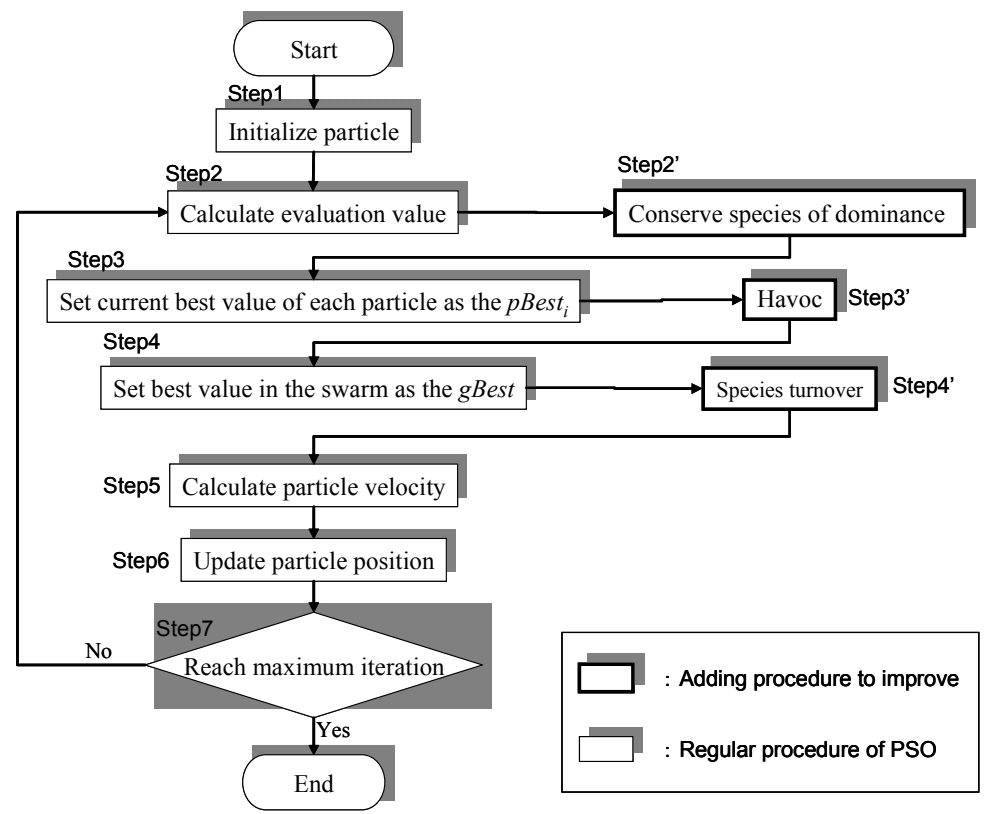

Figure 2: $\quad$ Procedure of the improved DPSO.

$$
a c_{i, j}=\left\{\begin{array}{cc}
1 & \text { affinity }_{i, j} \geq T_{\text {affinity } p p} \\
0 & \text { otherwise }
\end{array}\right.
$$

Where $T_{\text {affinity }} p p=$ threshold for a similarity and $N=$ total number of particles. If the concentration is higher than a threshold $T_{\text {density }}$, the particle is conserved as species of dominance.

Step3: Set current best value of each particle as the $p B e s t_{i}$

If the value is better than the current $p B e s t_{i}$ of the particle, the $p B e s t_{i}$ value is replaced with the current value.

If $p B e s t_{i}$ has not been updated at a fixed interval termed interval $p, N^{\prime}$ particles selected randomly is replaced with the particles produced by uniform random number.

Step4: Set best value in the swarm as the $g B e s t$

If the best value of $p B e s t_{i}$ is better than the current gBest, gBest is replaced with the best value and the particle number with the best value is stored. The affinity between $p B e s t_{i}$ and the species of dominance conserved is calculated. If this affinity is higher than threshold $T_{\text {affinity } p \text { Dominant }}$, this particle is considered as same species. Next, the affinity between $g B B e s_{i}$ and the previous species of dominance is also calculated. If this affinity is better than threshold $T_{\text {affinity gDominant, }}$, this particle is replaced with a particle positioned best among low affinity particles. 
Step5: Calculate particle velocity

Calculate a velocity vector for each particle by using the particle's memory and the knowledge gained by the swarm based on eqn. (1).

Step6: Update particle position

Update the position of each particle by using its velocity vector and previous position based on eqns. (6) and (7).

$$
\text { if } \begin{array}{r}
\rho_{i}^{k+1}<\operatorname{sig}\left(v_{i}^{k+1}\right) \text { then } x_{i}^{k+1}=1 ; \\
\text { else } x_{i}^{k+1}=0 \\
\operatorname{sig}\left(v_{i}^{k+1}\right)=\frac{1}{1+\exp \left(-v_{i}^{k+1}\right)}
\end{array}
$$

where, $\rho$ is uniform random number [0,1], $\operatorname{sig}\left(v_{i}^{k+1}\right)$ is Sigmoid function.

Step7: Reach maximum iteration

If iteration number reaches the maximum iteration, then exit. Otherwise, go to Step2.

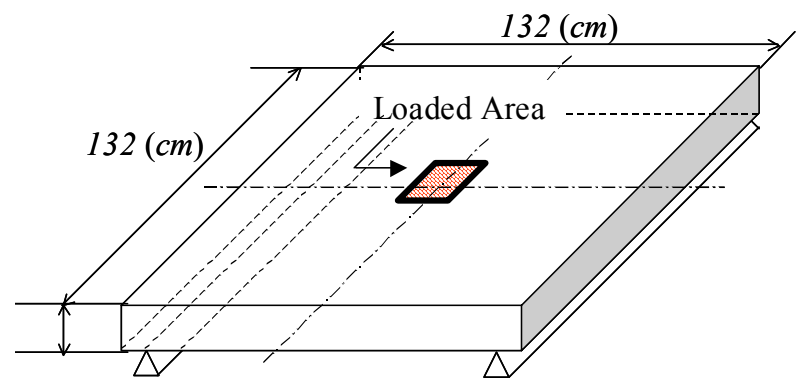

Figure 3: $\quad$ Reinforced concrete slab.

\section{Application to impact resistance design of RC slab}

As an example of an application of the improved DPSO algorithm to the design of a structure, an impact resistance design support system of a reinforced concrete (RC) slab under impact load is described.

The RC slab designed in this study is shown in fig. 3. It is $132 \mathrm{~cm}$ wide and $132 \mathrm{~cm}$ long square RC slab with double reinforcement. The slab thickness is a design variable. The RC slab is supported on both sides with a span length of $120 \mathrm{~cm}$.

$\mathrm{RC}$ slabs subjected to impact load need to be designed to resist great impact through an effective combination of parameters such as the type and slab thickness of concrete, the type, number, and diameter of the reinforcing bars. For evaluating impact resistance, the results of the analysis of an impact induced failure using a dynamic nonlinear finite element method (FEM) are used as such analysis has been made possible owing to the recent advancement of numerical 
analysis method. Since a dynamic nonlinear analysis requires much computation time, and a large number of design parameters are involved, a computation for all combinations of parameters for examining design alternatives is impracticable. Therefore application of the improved DPSO algorithm is suggested to present design alternatives.

\subsection{Outline of multilayer finite element analysis [4]}

In this study, multilayer FEM model as shown in fig. 4 is used for analyzing the behavior of a RC slab subjected to an impact load. This method enables an elastoplastic analysis by vertically dividing the RC slab into several layers, applying a bending finite element analysis of a thin layer to each layer, and using a multilayer analysis. In this study, only a quarter of the RC slab is analyzed in view of the symmetry of this slab as shown in fig. 5 .
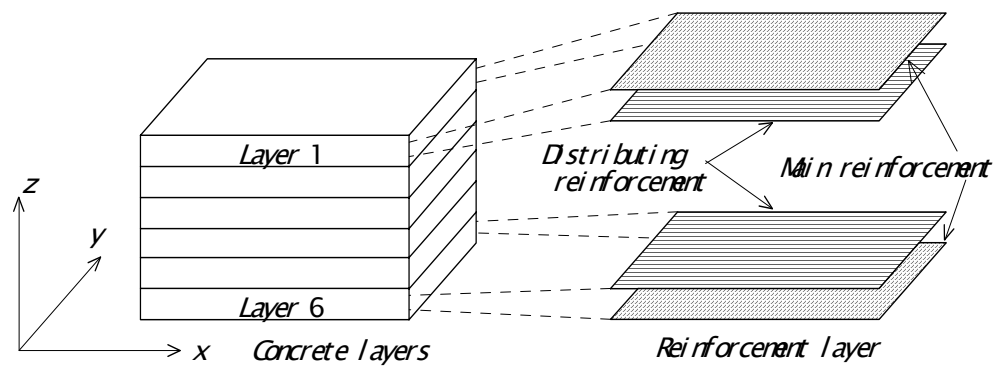

Figure 4: $\quad$ Multilayer finite element model.

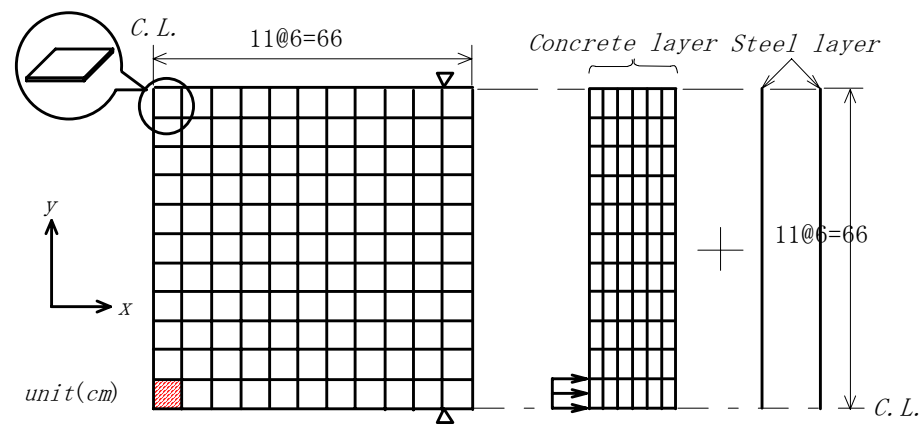

Figure 5: $\quad$ Analysis model (quater portion).

Prior to design simulation, a numerical simulation of impact test was conducted in order to examine an accuracy of the multilayer FEM. The impact test was carried out using pendulum type apparatus as shown in fig. 6 . In this test, several types of concrete and reinforcing bar were used. The RC slab specimen is the $132 \mathrm{~cm}$ wide and $132 \mathrm{~cm}$ long square with double reinforcement. As an example of numerical simulation, calculation of the RC slab having 
normal strength concrete and ordinary reinforcing bar was performed. Comparison of relation between impact force and displacement at the center of specimen is shown in fig. 7. As is obvious from this figure, both curves show good agreement in terms of the feature of load histories such as maximum impact load and softening behavior.

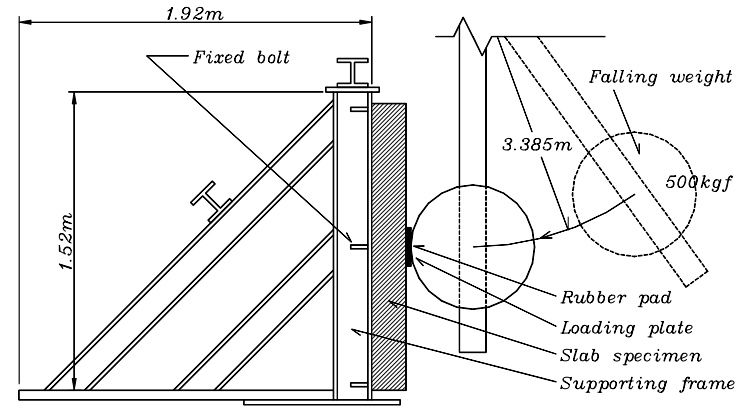

Figure 6: $\quad$ Outline of test.

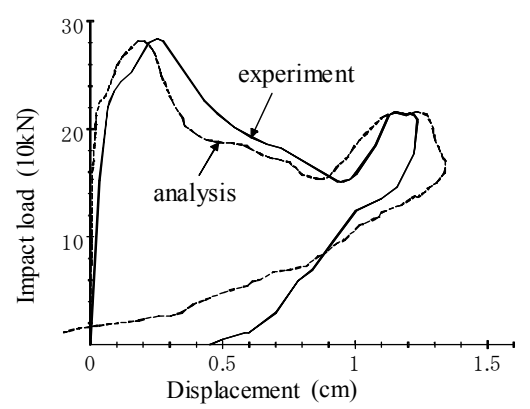

Figure 7: Results of analysis.

\subsection{Material model and impact load in design simulation}

The types of concrete used in design simulation are normal strength concrete, high strength concrete and steel fiber mixed concrete as shown in fig. 8. The types of reinforcement are ordinary bar, high strength bars, type A FRP and type B FRP bar. Only one layer of reinforcement is set at upper and lower side. Impact load used in analysis is idealized as triangular pulse as shown in fig. 9 . The rate of loading is set to $500 \mathrm{k} \mathrm{N} / \mathrm{ms}$.

\subsection{Evaluating indexes}

In this study, three indexes below are employed to evaluate the impact performance of RC slab. These indexes are obtained by FEM analysis. 


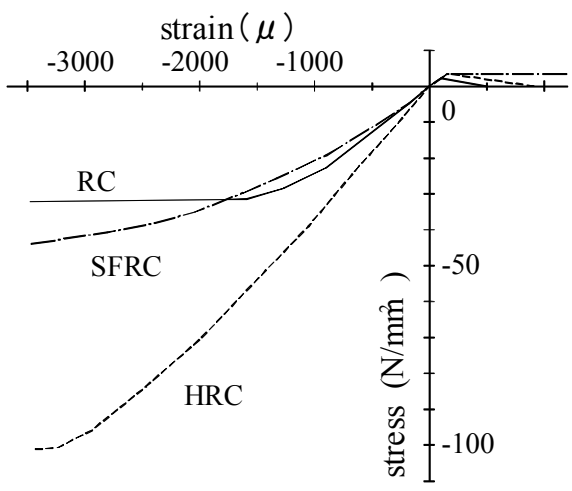

Figure 8: Stress strain curve for Figure 9: Idealized impact load.

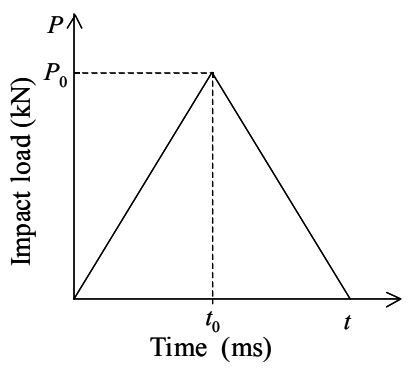
concrete.

\subsubsection{Impact load at a failure $\boldsymbol{P}_{\boldsymbol{f}}$}

According to test results, the larger the impact load at a failure, the smaller failure is. That is, a sound structure shows higher impact load. The higher the impact load at a failure, the higher load bearing capacity the structure has.

\subsubsection{Local deformation index $I_{L}$}

The local deformation index below is proposed by Miyamoto et al. [4].

$$
I_{L}=\frac{\phi}{\delta_{u}}
$$

where, $\phi$ is a curvature, and $\delta_{u}$ is a displacement of the point of loading.

The local deformation index is calculated based on the displacement of the slab obtained by finite element analysis. This value has a close correlation with the failure mode. If the local deformation is smaller, the value of index is smaller and failure mode shows a bending.

\subsubsection{Impact resistance evaluation function $\boldsymbol{I}_{\text {imp }}$}

In order to evaluate the impact resistant performance of $\mathrm{RC}$ slab, an impact resistance evaluation function $I_{i m p}$ was proposed by Emoto et al. [5] using local deformation index $I_{L}$ and the impact load at a failure $P_{f}$ is used as follows:

$$
I_{i m p}=\frac{P_{f}}{I_{L}}
$$

A RC slab has higher performance to resist impact with larger value of the impact resistance evaluation function. 
Table 1: $\quad$ List of properties and codes for RC slabs.

\begin{tabular}{|c|c|c|}
\hline Parameter & type & Code \\
\hline \multirow{4}{*}{ Slab thickness } & 11.05 & 00 \\
\hline & 11.70 & 01 \\
\hline & 12.35 & 10 \\
\hline & 13.00 & 11 \\
\hline \multirow{3}{*}{ Concrete } & Normal strength & 00 \\
\hline & High strength & 01 \\
\hline & Steel fiber mixed & 10 \\
\hline \multirow{4}{*}{ Reinforcement } & Ordinary & 00 \\
\hline & High strength & 01 \\
\hline & Type A FRP & 10 \\
\hline & Type B FRP & 11 \\
\hline \multirow{6}{*}{ Diameter of rebar } & D13 & 010 \\
\hline & D16 & 011 \\
\hline & D19 & 100 \\
\hline & D22 & 101 \\
\hline & D25 & 110 \\
\hline & D29 & 111 \\
\hline \multirow{4}{*}{ Number of rebar } & 4 & 001 \\
\hline & 6 & 011 \\
\hline & 8 & 101 \\
\hline & 10 & 111 \\
\hline
\end{tabular}

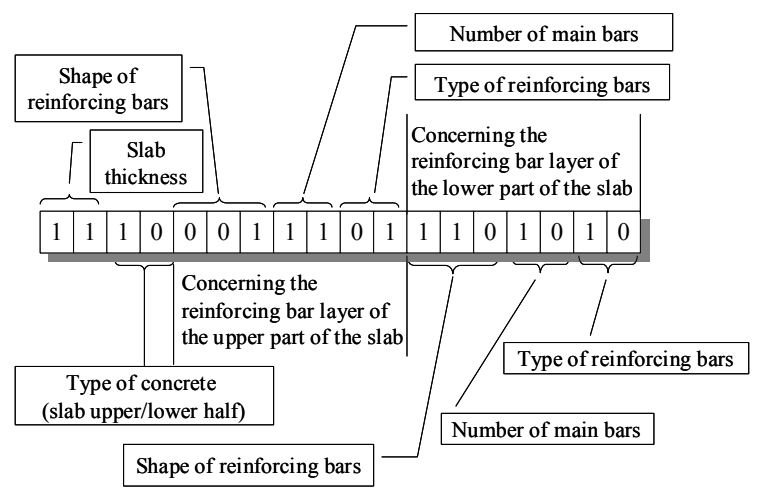

Figure 10: Example of coding.

\subsection{Coding and constraint condition}

In order to combine an FE analysis with the improved DPSO, the properties of a RC slab need to be expressed in binary codes. The properties of the RC slab here mean the elements constituting the slab such as the type, the quantity and the diameter of reinforcing bars, and type and the thickness of the concrete. Since the code of each element is set at a power of two as much as possible 
because a binary system is used. The coding of properties of the RC slab is listed in table 1. An example of coding is shown in fig. 10. The number of possible combinations was 110,592 . In order to verify the result of design simulation, all combinations of parameters were calculated before design simulation. Constraint condition is that maximum weight of the RC slab is $5.4 \mathrm{kN}(540 \mathrm{~kg})$.

\subsection{Design simulation}

Here, design simulations are carried out for three indexes described above. In a calculation of the improved DPSO, the number of particle is set to 15 , and the threshold are set to $T_{\text {density }}=0.45, T_{\text {density } p p}=0.80, T_{\text {affinity } p \text { Dominant }}=0.80$, $T_{\text {affinity_gDominant }}=0.125$, interval_ $p=5$ and interval_ $g=10$.

\subsubsection{Optimization design by impact load at a failure}

Objective function:

To design a RC slab with a higher value of an impact load at a failure

Ten best design plans calculated beforehand are shown in table 2 . The RC slab models in the shaded boxes (italicized) indicate the design alternatives obtained by the improved DPSO using the impact load at a failure as evaluating index. In this table, the impact loads obtained by FE analysis in first through fifth design plans are same values of 1,375,000 N. The improved DPSO provides three design alternatives among them and ninth design alternative. This result means that multiple solutions exist in this problem, and the improved DPSO could provide practical multiple design plans usefully.

A common feature of these plans is rich reinforcement in upper part. This may be caused because the impact load is getting larger when stiffness of surface of structure is high.

\subsubsection{Optimization design by local deformation index}

\section{Objective function:}

To design a RC slab with a smaller value of a local deformation index

Ten best design plans calculated beforehand are shown in table 3 . The RC slab models in the shaded boxes (italicized) indicate the design alternatives obtained by the improved DPSO using the local deformation index. In this table, the local deformation indexes in first and second design plans are same value of $0.1547 \times 10^{-2} / \mathrm{cm}^{2}$. The improved DPSO provides first through fourth and eighth best design alternatives.

A common feature of these plans is rich reinforcement in lower part. In this case, objective function suggests that bending mode is desirable. This demand results in rich reinforcement in lower part to yield ductile tensile failure before brittle compressive failure of concrete in upper part.

\subsubsection{Optimization design by impact resistance evaluation function}

\section{Objective function:}

To design a RC slab with a higher value of an impact resistance evaluation function. 


\begin{tabular}{|c|c|c|c|c|c|c|c|c|c|c|}
\hline 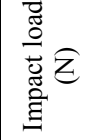 & 总 & 这 & $\begin{array}{l}8 \\
8 \\
\\
2\end{array}$ & 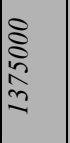 & $\begin{array}{l}8 \\
8 \\
2 \\
2 \\
-1\end{array}$ & $\begin{array}{l}8 \\
8 \\
\vdots \\
2 \\
2 \\
-1\end{array}$ & $\begin{array}{l}8 \\
\vdots \\
0 \\
n \\
n \\
n\end{array}$ & $\begin{array}{l}8 \\
8 \\
8 \\
0 \\
0 \\
\end{array}$ & $\begin{array}{l}8 \\
8 \\
\infty \\
2 \\
2\end{array}$ & 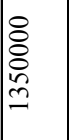 \\
\hline 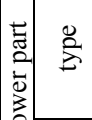 & 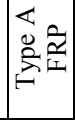 & 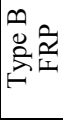 & 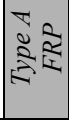 & 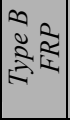 & 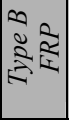 & 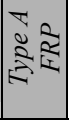 & 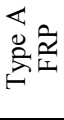 & 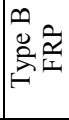 & 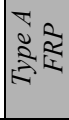 & 离 \\
\hline 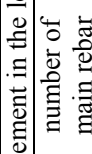 & I & $\cong$ & $\infty$ & $\infty$ & $\infty$ & $\approx$ & $\infty$ & $\infty$ & $\infty$ & $\simeq$ \\
\hline 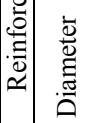 & $\frac{m}{\theta}$ & $\stackrel{m}{\vec{\omega}}$ & $\frac{m}{a}$ & $\frac{\pi}{\sigma}$ & $\frac{m}{a}$ & $\frac{m}{a}$ & $\overrightarrow{\vec{\theta}}$ & ลี & $\frac{n}{a}$ & $\frac{0}{0}$ \\
\hline 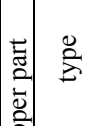 & 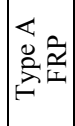 & 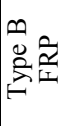 & $\begin{array}{l}\pi \\
\vdots \\
\vdots \\
\vdots \\
\underbrace{2}\end{array}$ & 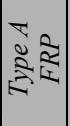 & 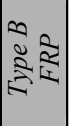 & 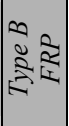 & 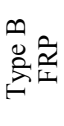 & 象总齐 & 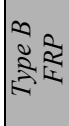 & 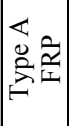 \\
\hline 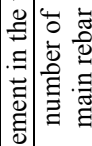 & 0 & $\infty$ & $\div$ & $\stackrel{\imath}{ }$ & $\stackrel{\sim}{\curvearrowright}$ & $\approx$ & $\stackrel{0}{\simeq}$ & $\because$ & $\stackrel{\curvearrowright}{\sim}$ & $\approx$ \\
\hline 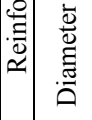 & $\frac{\partial}{\hat{\theta}}$ & ڤિ & $\tilde{\check{a}}$ & $\stackrel{\curvearrowright}{\check{a}}$ & $\check{\tilde{\theta}}$ & $\frac{m}{\sigma}$ & $\frac{0}{0}$ & $\frac{0}{0}$ & $\tilde{\widetilde{a}}$ & 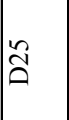 \\
\hline 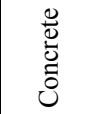 & 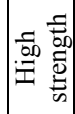 & 点章 & 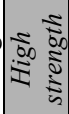 & 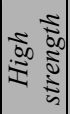 & 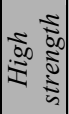 & 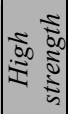 & 点 & 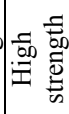 & 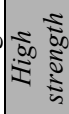 & 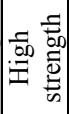 \\
\hline 丞总 & 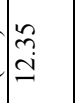 & 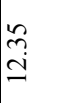 & 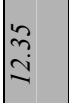 & 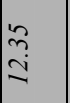 & $\begin{array}{l}\stackrel{n}{n} \\
\stackrel{n}{\sim}\end{array}$ & $\begin{array}{l}\tilde{n} \\
\stackrel{n}{i} \\
\end{array}$ & 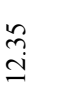 & 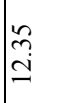 & $\mid \begin{array}{l}\stackrel{n}{\approx} \\
\stackrel{n}{\approx}\end{array}$ & 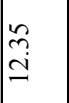 \\
\hline 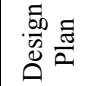 & - & N & $m$ & $\nabla$ & $n$ & 6 & $r$ & $\infty$ & a & $\varrho$ \\
\hline
\end{tabular}




\begin{tabular}{|c|c|c|c|c|c|c|c|c|c|c|}
\hline 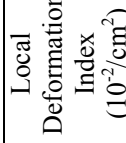 & $\frac{5}{2}$ & $\frac{7}{2}$ & $\begin{array}{l}\frac{8}{2} \\
\frac{2}{0}\end{array}$ & 㔯 & $\frac{n}{n}$ & $\begin{array}{l}\frac{m}{n} \\
\frac{n}{0} \\
0\end{array}$ & $\frac{n}{n}$ & $\frac{n}{2}$ & $\begin{array}{l}n \\
n \\
n \\
0 \\
0\end{array}$ & \begin{tabular}{l}
$n$ \\
$\tilde{n}$ \\
\hdashline \\
0
\end{tabular} \\
\hline 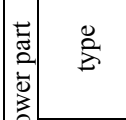 & 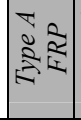 & 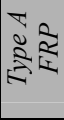 & 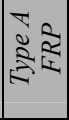 & 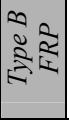 & 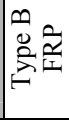 & 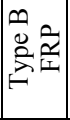 & 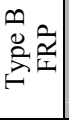 & 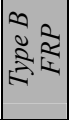 & 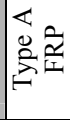 & 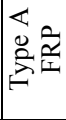 \\
\hline 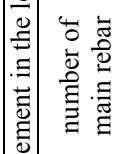 & $\curvearrowright$ & $\approx$ & $\stackrel{\curvearrowright}{\sim}$ & $\approx$ & 이 & 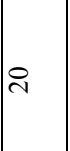 & 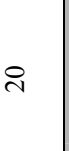 & $\approx$ & ஜ્ & กิ \\
\hline 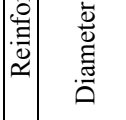 & ڤે & こิ & $\tilde{\imath}$ & ָิ & ิิ & ลิ & ลิ & ָे & ิิ & ิิ \\
\hline 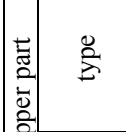 & 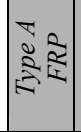 & 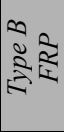 & 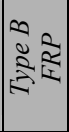 & 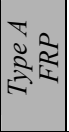 & 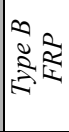 & 乍 & 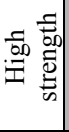 & 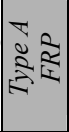 & 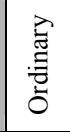 & 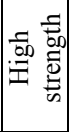 \\
\hline 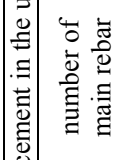 & 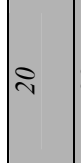 & $\curvearrowright$ & $\infty$ & $\infty$ & $\infty$ & $\infty$ & $\infty$ & $\approx$ & $\infty$ & $\infty$ \\
\hline 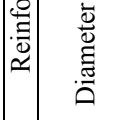 & $\frac{m}{\sigma}$ & $\frac{n}{a}$ & $\frac{m}{a}$ & $\frac{n}{a}$ & $\frac{m}{a}$ & $\frac{m}{a}$ & $\frac{m}{a}$ & $\stackrel{\pi}{a}$ & $\frac{m}{a}$ & $\frac{m}{a}$ \\
\hline $\begin{array}{l}\frac{0}{0} \\
0 \\
0 \\
0\end{array}$ & 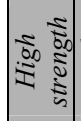 & 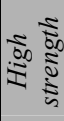 & 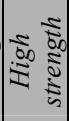 & $\left|\begin{array}{cc} & 5 \\
500 & 50 \\
0 & 0 \\
0 & 5\end{array}\right|$ & 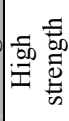 & 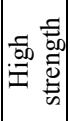 & 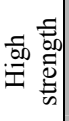 & 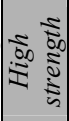 & 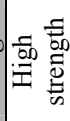 & 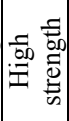 \\
\hline 㞼兽 & $\begin{array}{l}\dddot{n} \\
\stackrel{n}{\sim}\end{array}$ & $\begin{array}{l}\stackrel{n}{2} \\
\stackrel{n}{\approx}\end{array}$ & $\begin{array}{l}\stackrel{n}{2} \\
\stackrel{\sim}{\sim}\end{array}$ & $\mid \begin{array}{l}\stackrel{n}{2} \\
\stackrel{n}{\approx}\end{array}$ & $\begin{array}{l}\stackrel{\sim}{2} \\
\stackrel{\sim}{\simeq}\end{array}$ & 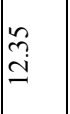 & 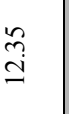 & $\mid \begin{array}{l}n \\
\stackrel{2}{\approx} \\
\approx\end{array}$ & 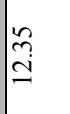 & $\mid \begin{array}{r}\tilde{n} \\
\stackrel{\sim}{c}\end{array}$ \\
\hline 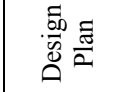 & - & $\sim$ & $m$ & $\nabla$ & in & 6 & $r$ & $\infty$ & a & 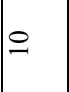 \\
\hline
\end{tabular}




\begin{tabular}{|c|c|c|c|c|c|c|c|c|c|c|}
\hline 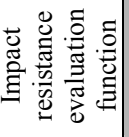 & $\mid \begin{array}{l}\infty \\
\infty \\
\infty \\
\infty \\
\infty \\
\infty\end{array}$ & $\underset{\substack{\frac{2}{a} \\
\infty}}{\stackrel{2}{a}}$ & $\begin{array}{l}\frac{1}{2} \\
\frac{7}{2} \\
0 \\
\infty\end{array}$ & 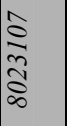 & 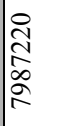 & 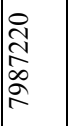 & 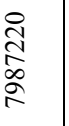 & $\begin{array}{l}\infty \\
\stackrel{\infty}{a} \\
\infty \\
\curvearrowright\end{array}$ & $\begin{array}{l}\frac{5}{2} \\
\frac{2}{2} \\
\frac{2}{2}\end{array}$ & $\mid \begin{array}{l}\infty \\
0 \\
0 \\
\infty \\
\infty \\
\infty \\
2\end{array}$ \\
\hline 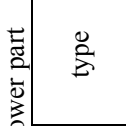 & \begin{tabular}{l}
$\infty$ \\
0 \\
0 \\
$\vdots$ \\
\multirow{2}{*}{}
\end{tabular} & 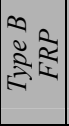 & 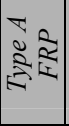 & $\begin{array}{ll}\infty & \\
0 & 2 \\
\vdots & 0\end{array}$ & 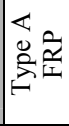 & 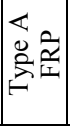 & 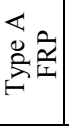 & 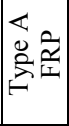 & 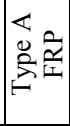 & 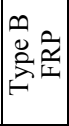 \\
\hline 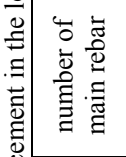 & 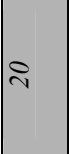 & 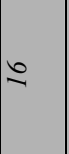 & $\approx$ & $\approx$ & $\stackrel{0}{-}$ & $\underline{-}$ & $\underline{-}$ & $\cong$ & $\simeq$ & $\simeq$ \\
\hline 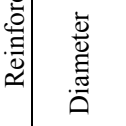 & $\frac{\circ}{a}$ & Әे & 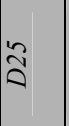 & 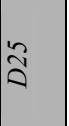 & ڤิ & Әे & Әิ & તิ & $\frac{m}{\theta}$ & $\frac{m}{a}$ \\
\hline 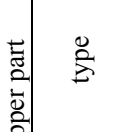 & 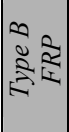 & $\mid \begin{array}{ll}\nabla & 2 \\
\vdots & \frac{\pi}{2} \\
\vdots & 0\end{array}$ & \begin{tabular}{ll}
$\infty$ & 0 \\
0 & $\frac{2}{2}$ \\
\multirow{2}{*}{} & $\frac{2}{12}$
\end{tabular} & 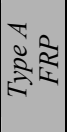 & 死 & 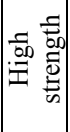 & 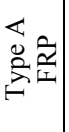 & 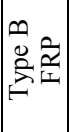 & 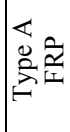 & 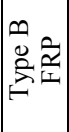 \\
\hline 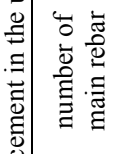 & $\infty$ & 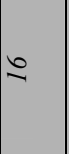 & $\infty$ & $\infty$ & $\infty$ & $\infty$ & $\infty$ & $\stackrel{\sim}{\circ}$ & 0 & $\infty$ \\
\hline 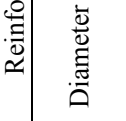 & $\tilde{\tilde{a}}$ & $\frac{2}{a}$ & $\frac{m}{a}$ & $\frac{1}{a}$ & $\frac{m}{\bar{a}}$ & $\frac{m}{a}$ & $\frac{m}{\vec{\rho}}$ & $\stackrel{\partial}{\vec{\rho}}$ & $\frac{\partial}{\vec{\theta}}$ & ڤิ \\
\hline 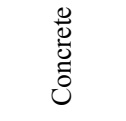 & 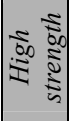 & 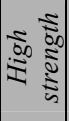 & 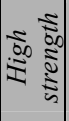 & 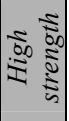 & 总 & 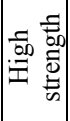 & 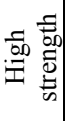 & 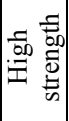 & 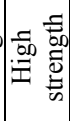 & 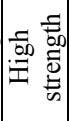 \\
\hline 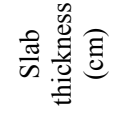 & $\begin{array}{l}\dddot{n} \\
\stackrel{n}{\sim}\end{array}$ & $\stackrel{\Re}{\stackrel{n}{2}}$ & 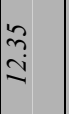 & 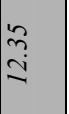 & 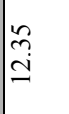 & $\begin{array}{l}\stackrel{n}{2} \\
\end{array}$ & 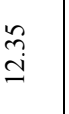 & 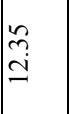 & 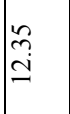 & 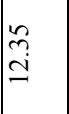 \\
\hline 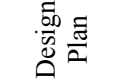 & - & $\sim$ & $m$ & $\nabla$ & in & 0 & $r$ & $\infty$ & $a$ & 잉 \\
\hline
\end{tabular}



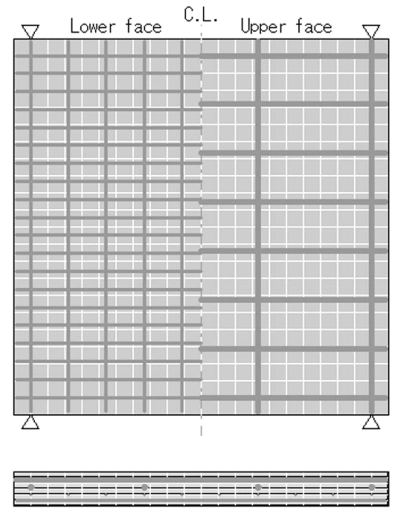

\section{Design plan 1}
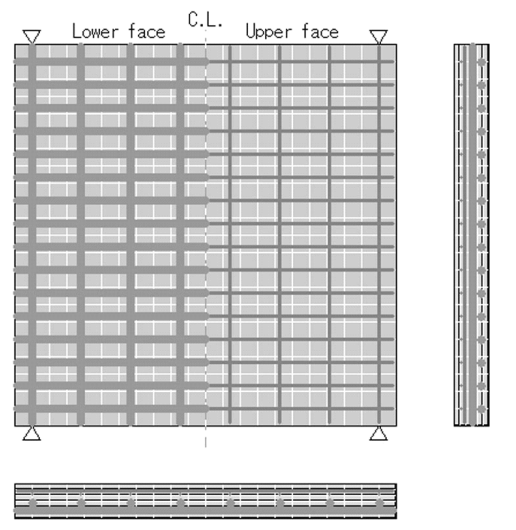

[Concrete]

Upper part: High-strength concrete

Lower part: High-strength concrete

Slab thickness: $12.35 \mathrm{~cm}$

[Reinforcement]

Main reinforcement in the upper part Type B FRP bars Shape: D22; 8 bars

Distributing reinforcement in the upper part Type B FRP bars Shape: D22; 4 bars

Main reinforcement in the lower part Type B FRP bars Shape: D16; 20 bars

Distributing reinforcement in the lower part Type B FRP bars Shape: D16; 10 bars

per part: High-strength concrete

Slab thickness: $12.35 \mathrm{~cm}$

[Reinforcement]

Main reinforcement in the upper part Type A FRP bars Shape: D13; 16 bars

Distributing reinforcement in the upper part Type A FRP bars Shape: D13; 8 bars

Main reinforcement in the lower part Type B FRP bars Shape: D29; 16 bars

Distributing reinforcement in the lower part Type B FRP bars Shape: D29; 8 bars

\section{Design plan 2}

Figure 11: First and second design plans.

Ten best design plans are shown in table 4. The RC slab models in the shaded boxes (italicized) indicate the design alternatives. As is obvious table 4, the improved DPSO provided first through fourth best fitting design alternatives. First and second design plans are shown in fig. 11. The impact resistance evaluation function is an index combined impact load at a failure and a local deformation index, and represents an amount of energy absorption. Thus, these $\mathrm{RC}$ slabs have large capacity for impact in term of energy absorption.

These design simulations demonstrated that useful multiple design alternatives were provided by combining the improved DPSO with finite element method. 


\section{Conclusions}

In this study, PSO algorithm was applied to the optimal design of RC slab under impact load. In order to provide multiple solutions, discrete type of PSO was improved adopting ecological logic. Then, some design simulations were performed using the improved DPSO. The conclusions of this study are summarized below:

(1) DPSO was improved by adopting ecological logic to provide multiple design alternatives.

(2) It was confirmed that combination of the improved DPSO and multilayer finite element method enables impact resistance design for a $\mathrm{RC}$ slab with highly accuracy.

(3) Useful design plans were provided by using the three evaluating indexes. Degree of freedom in design simulation is higher by setting appropriate index for actual purpose.

\section{References}

[1] D. E. Goldberg, Genetic algorithms in search, optimization, and machine learning, Addison-Wesley, 1989.

[2] J. Kennedy, R. Eberhart, Particle swarm optimization, Proc. of IEEE International Conference on Neural Networks, Vol. IV, pp. 1942-1948, 1995.

[3] J. Kennedy, R. Eberhart, A discrete binary version of the particle swarm optimization algorithm, Proc. of the 1997 conference on System, Man, and Cybernetics, pp.4104-4109, 1997.

[4] Miyamoto, A., King, M., and Fujii, M., Nonlinear dynamic analysis of reinforced concrete slabs under impulsive loads. ACI struct. J., 88(4), pp. 411-419, 1991.

[5] Emoto, H., Nakamura, H., Miyamoto, A., Development of impact resistance design support system for RC slabs by genetic algorithms. J. Struct. Eng., 45A, pp. 453-464, 1999. 